\title{
PERLINDUNGAN NASABAH BANK DARI TINDAKAN KEJAHATAN SKIMMING DI TINJAU DARI UNDANG UNDANG NOMOR 21 TAHUN 2011 TENTANG OTORITAS JASA KEUANGAN
}

Yulianti $^{1}$

${ }^{1}$ Fakultas Hukum, Universitas Antakusuma

\begin{abstract}
ABSTRAK
Perlindungan Nasabah Bank adalah Upaya memberikan kepastian hukum kepada nasabah Bank Kejahatan Skiming adalah Tindak kejahatan kegiatan atau upaya seseorang untuk membobol data dari pita magnetik kartu ATM/Debit sehingga sang pelaku berdasarkan Undang Undang Nomor 21 tahun 2011 tentang Otoritas Jasa Keuangan.dapat mengetahui data dari korban Secara ilegal. Otoritas Jasa Keuangan Adalah Lembaga yang independen dan bebas dari campur tangan pihak lain, yang mempunyai fungsi, tugas, dan wewenang pengaturan, pengawasan, pemeriksaan dan penyidikan sebagaimana di maksud dalam UU nomor 21 tahun 2011. Selain penerapan Undang undang secara tegas, Bank juga harus memberikan pendididkan dan pengetahuan kepada nasabah bagaimaan cara menghindari kejahatan skimming.
\end{abstract}

\section{ARTICLE INFO}

Kata Kunci:

Perlindungan nasabah

Bank; Kejahatan

Skimming; Otoritas Jasa

Keuangan

Cite this paper:

Yulianti, 2020.

Perlindungan Nasabah

Bank Dari Tindakan

Kejahatan Skimming Di

Tinjau Dari Undang

Undang Nomor 21

Tahun 2011 Tentang

Otoritas Jasa Keuangan.

Widya Yuridika: Jurnal

Hukum, 3(2).

\section{PENDAHULUAN}

Bank adalah sebuah badan usaha yang menghimpun dana dari masyarakat dalam bentuk simpanan dan menyalurkannya kepada masyarakat dalam bentuk kredit dan atau bentuk-bentuk lain dengan tujuan untuk meningkatkan taraf hidup orang banyak. ( Arti bank menurut Undang-undang RI nomor 10 Tahun 1998 tanggal 10 November 1998 tentang perbankan pasal 1 ayat 2. ). Sedangkan Perbankan adalah segala sesuatu yang menyangkut tentang bank,mencakup kelembagaan, kegiatan usaha, serta cara dan proses dalam melaksanakan kegiatan usahanya. Kita semua tahu bahwa industri Perbankan adalah industri jasa berdasarkan kepercayaan. Perbankan mempunyai fungsi utama sebagai intermediasi, yaitu penghimpun dana dari masyarakat dan menyalurkannya 
secara efektif dan efisien pads sector-sektor riil untuk menggerakkan pembangunan dan stabilitas perekonomian sebuah Negara. Dalam hal ini, bank menghimpun dana dari masyarakat berdasarkan asas kepercayaan masyarakat. Apabila masyarakat percaya pada bank, maka masyarakat akan merasa aman untuk menyimpan uang atau dananya di bank. Bank harus selalu menjaga tingkat kepercayaan dari nasabah atau masyarakat agar menyimpan dana mereka di bank, dan bank dapat menyalurkan dana tersebut untuk menggerakkan perekonomian bangsa. Jasa bank sangat penting dalam pembangunan ekonomi suatu Negara. Jasa perbankan pada umumnya terbagi atas dua tujuan. Pertama, sebagai penyedia mekanisme dan alat pembayaran yang efisien bagi nasabah. Untuk ini, bank menyediakan uang tunai, tabungan, dan kartu kredit. Ini adalah peran bank yang paling penting dalam kehidupan ekonomi. Kedua, dengan menerima tabungan dari nasabah dan meminjamkannya kepada para pihak yang membutuhkan dana, berarti bank meningkatkan arus dana untuk investasi dan pemanfaatan yang lebih produktif (Lukman Santoso, 2011: 32). Dan Pengawasan Perbankan berdasarkan Undang Undang Nomor 21 Tahun 2011 pasal 55 ayat 2 tentang Otoritas Jasa Keuangan, sejak Sejak tanggal 31 Desember 2013, fungsi, tugas, dan wewenang pengaturan dan pengawasan kegiatan jasa keuangan di sektor Perbankan beralih dari Bank Indonesia ke Otoritas Jasa Keuangan.

Terjadinya proses globalisasi dalam sistem keuangan dan pesatnya kemajuan di bidang teknologi informasi serta inovasi finansial telah menciptakan sistem keuangan yang sangat kompleks, dinamis, dan saling terkait antar-subsektor keuangan baik dalam hal produk maupun kelembagaan. Di samping itu, adanya lembaga jasa keuangan yang memiliki hubungan kepemilikan di berbagai subsektor keuangan (konglomerasi) telah menambah kompleksitas transaksi dan interaksi antarlembaga jasa keuangan di dalam sistem keuangan. ( Penjelasan Undang Undang Republik Indonesia Nomor 21 tahun 2011 tentang OJK ). Banyaknya permasalahan lintas sektoral di sektor jasa keuangan, yang meliputi tindakan moral hazard, belum optimalnya perlindungan konsumen jasa keuangan, dan terganggunya stabilitas sistem keuangan semakin mendorong diperlukannya pembentukan lembaga pengawasan di sektor jasa keuangan yang terintegrasi. ( Penjelasan Undang Undang Republik Indonesia Nomor 21 tahun 2011 tentang OJK ) Sehubungan dengan hal tersebut di atas, Pengawasan Perbankan berdasarkan Undang Undang Nomor 21 Tahun 2011 pasal 55 ayat 2 tentang Otoritas Jasa Keuangan, sejak Sejak tanggal 31 Desember 2013, fungsi, tugas, dan wewenang pengaturan dan pengawasan kegiatan jasa keuangan di sektor Perbankan beralih dari Bank Indonesia ke Otoritas Jasa Keuangan.

Pengawasan tersebut di dalam prakteknya tentu banyak hambatan dan kendala dalam mempertahankan kepercayaan dari masyarakat terhadap sebuah bank. Kita ketahui bersama bahwa pada tahun 2018, terdapat banyak sekali kasus yang terdengar mengenai metode penipuan Bank bernama Skimming sehingga Skimming Bank bukanlah hal baru yang terjadi di Indonesia. Mungkin sebagian masyarakat belum mengetahui bagaimana metode penipuan ini bekerja sehingga tak sedikit masyarakat yang terjerat oleh pelaku Skimming. Lalu, apa itu Skimming?

Teknik Skimming adalah kegiatan atau upaya seseorang untuk membobol data dari pita magnetik kartu ATM/Debit sehingga sang pelaku dapat mengetahui data dari korban. Selanjutnya, setelah melakukan teknik tersebut sang pelaku dapat mengakses data korban secara illegal. Teknik skimming menggunakan alat yang sengaja diletakkan pada slot mesin ATM. Alat yang digunakan pelaku bernama skimmer. Dengan alat tersebut, sang pelaku dapat menggunakan data yang terdapat pada magnetic stripe di ATM sang korban. Untuk kasus kasus kejahatan skimming yang terjadi di Indoneisa, polisi berhasil 
menangkap komplotan pembobol uang nasabah bank yang bernama Caitanovici Andrean Stepan, Raul Kalai, dan Ionel Robert Lupu asal Romania, serta Ferenc Hugyec dari Hongaria. Satu orang lagi yang ditangkap yakni Milah Karmilah, warga negara Indonesia yang turut membantu aksi para tersangka. Kabid Humas Polda Metro Jaya Kombes Argo Yuwono menyebut skimming sebagai bentuk "penjajahan" warga asing di Indonesia. Oleh karena itu, polisi terus menangkap para pelaku kejahatan tersebut. "Ini tidak bosanbosannya ya tersangka dari luar negeri yang ke Indonesia. Jadi, jangan sampai negara kita nanti akan 'dijajah' oleh para penikmat ini yang melakukan tindak pidana di Indonesia," ujar Argo di Mapolda Metro Jaya, Sabtu (17/3/2018). Selain pelaku kejahatan skimming asal Bulgaria, Romania, dan Hongaria, polisi mengaku pernah menangkap warga negara Slovenia dan Kroasia yang melakukan tindak pidana serupa. ( Sumber Detik News , 18 Maret 2018).

Liputan6.com, Jakarta - Belakangan ini kejahatan perbankan berupa pengurasan uang nasabah di ATM melalui metode skimming semakin marak. Yang mengejutkan, pelakunya ternyata sebagian besar warga negara asing (WNA). Kejahatan dengan metode ini sebenarnya bukan hal baru. Namun banyak nasabah yang menjadi korban kejahatan skimming baru-baru ini, membuat publik Tanah Air resah. Bagaimana tidak, uang di ATM hilang tiba-tiba tanpa jejak.

Skimming merupakan salah satu tindak kejahatan dalam cyber crime dimana kejahatan ini dilakukan melalui jaringan sistem komputer, baik lokal maupun global, dengan memanfaatkan teknologi dengan cara menyalin informasi yang terdapat pada magnetic stripe Kartu ATM secara illegal untuk memiliki kendali atas rekening korban. Pelaku cyber crime ini memiliki latar belakang kemampuan yang tinggi di bidangnya sehingga sulit untuk melacak dan memberantasnya secara tuntas. (Budi Suhariyanto, Tindak Pidana Teknologi Informasi (Cybercrime): Urgensi Pengaturan dan Celah Hukumnya, Jakarta: Rajawali Press, 2013.

Skimming adalah aktivitas yang berkaitan dengan upaya pelaku untuk mencuri data dari pita magnetik kartu ATM/debit secara ilegal untuk memiliki kendali atas rekening korban. Modus operasinya adalah mengkloning data dari magnetic srtripe yang terdapat pada kartu ATM milik nasabah. ( Liputan 6.Com, Jakarta, 17/3/2018 ) Komplotan penjahat pembobolan ATM dengan skimming diketahui sebagian besar warga asing setelah anggota Subdit Resmob Polda Metro Jaya menangkap tiga WNA asal Rumania dan 1 WNA dari Hungaria pekan ini. Tiga WNA Rumania itu berinisial CAS (27), RK alias LM (27), IRL (28) dan satu asal Hungaria inisial FH (26). Kasubdit Resmob Ditreskrimum Polda Metro Jaya AKBP Aris Priyono menyebut, selain empat WNA itu, pihaknya juga mengamankan WNI berinisial MK (30). Kelimanya ditangkap di tempat berbeda. "Ada tiga lokasi ya (penangkapan) di Serpong dan satu di NTB di Lombok," kata AKBP Aris Priyono kepada Liputan6.com, Jakarta, Jumat 16 Maret 2018.

Selain mengamankan pelaku, polisi juga megamankan puluhan barang bukti terkait kejahatan skimming. "Ada sekitar seribuan kartu ATM yang telah diisi dengan data curian dan alat untuk membuat Skimmer," ujar Aris.

Dia mengungkapkan, kelima tersangka terhitung sudah hampir setahun menjalankan aksinya. Para WNA itu datang ke Indonesia menggunakan visa turis. Aris mengatakan, penyidik saat ini tengah mendalami kaitan lima orang ini dengan pelakupelaku lain. Sebab bukan tidak mungkin para pelaku memiliki kelompok atau jaringan yang beroperasi di Indonesia. "Masih diselidiki apakah ada hubungan dengan kasus skimming yang sebelum-sebelumnya," ucap Aris. Dari hasil pemeriksaan sementara, kelima pelaku diketahui telah menyebar alat skimmer ke kota-kota besar di Indonesia. 
Dari pemeriksaan sementara juga muncul dugaan ada pelaku lain yang ikut membantu memasang alat skimming. Selain di Jakarta di Kota Kediri juga pernah terjadi kejahatan Skimming yang menimpa pada Bank plat Merah di kota tersebut. ( Sumber Investor Daily). Dari banyaknya kasus kejahatan skimming yang terjadi di Indonsia maka penulis tertarik melakukan penelitian yang berjudul : "PERLINDUNGAN NASABAH BANK DARI TINDAKAN KEJAHATAN SKIMMING DI TINJAU DARI UNDANG UNDANG NOMOR 21 TAHUN 2011 TENTANG OTORITAS JASA KEUANGAN"

Tujuan Penelitian ini adalah untuk mengethaui bagaimana perlindungan hukum terhadap nasabah korban kejahatan dengan metode skimming ditinjau dari Undang Undang Nomor 21 tahun 2011 tetntang Otoritas Jasa Keuangan. Mengetahui Upaya yang di lakukan Bank untuk mencegah Tindakan kejahatan Skimming. Kendala yang di hadapi Bank dalam pencegahan tindakan kejahatan Skimming.

Penelitian ini menggunakan Metode Penelitian Hukum Normatif-Empiris, yaitu Metode penelitian hukum yang pada dasarnya merupakan penggabungan antara pendekatan hukum normatif dengan adanya penambahan berbagai unsur empiris. Metode penelitian normatif-empiris mengenai implementasi ketentuan hukum normatif (undang-undang) dalam aksinya pada setiap peristiwa hukum tertentu yang terjadi dalam suatu masyarakat.

\section{HASIL DAN PEMBAHASAN}

1. Bagaimana perlindungan hukum terhadap nasabah korban kejahatan dengan metode skimming ditinjau dari Undang Undang Nomor 21 tahun 2011 tetntang Otoritas Jasa Keuangan.

Sebagaimana pada Bab VI Perlindungan Konsumen dan Masyarakat, Undang Undang Nomor 21 tahun 2011 tetntang Otoritas Jasa Keuangan, pada pasal 28 yang berbunyi Untuk perlindungan Konsumen dan masyarakat, OJK berwenang melakukan tindakan pencegahan kerugian Konsumen dan masyarakat, yang meliputi: a. Memberikan informasi dan edukasi kepada masyarakat atas karakteristik sektor jasa keuangan, layanan, dan produknya;

b. meminta Lembaga Jasa Keuangan untuk menghentikan kegiatannya apabila kegiatan tersebut berpotensi merugikan masyarakat; dan

c. tindakan lain yang dianggap perlu sesuai dengan ketentuan peraturan perundangundangan di sektor jasa keuangan.

Pada pasal 29 Undang Undang Nomor 21 tahun 2011 tetntang Otoritas Jasa Keuangan berbunyi

OJK melakukan pelayanan pengaduan Konsumen yang meliputi:

a. Menyiapkan perangkat yang memadai untuk pelayanan pengaduan Konsumen yang dirugikan oleh pelaku di Lembaga Jasa Keuangan;

b. Membuat mekanisme pengaduan Konsumen yang dirugikan oleh pelaku di Lembaga Jasa Keuangan; dan

c. Memfasilitasi penyelesaian pengaduan Konsumen yang dirugikan oleh pelaku di Lembaga Jasa Keuangan sesuai dengan peraturan perundang-undangan di sektor jasa keuangan.

Sedangkan pada pasal Pasal 30, mengatakan

(1) Untuk perlindungan Konsumen dan masyarakat, OJK berwenang melakukan pembelaan hukum, yang meliputi: 
a. memerintahkan atau melakukan tindakan tertentu kepada Lembaga Jasa Keuangan untuk menyelesaikan pengaduan Konsumen yang dirugikan Lembaga Jasa Keuangan dimaksud;

b. mengajukan gugatan:

1. untuk memperoleh kembali harta kekayaan milik pihak yang dirugikan dari pihak yang menyebabkan kerugian, baik yang berada di bawah penguasaan pihak yang menyebabkan kerugian dimaksud maupun di bawah penguasaan pihak lain dengan itikad tidak baik; dan/atau

2. untuk memperoleh ganti kerugian dari pihak yang menyebabkan kerugian pada Konsumen dan/atau Lembaga Jasa Keuangan sebagai akibat dari pelanggaran atas peraturan perundang-undangan di sektor jasa keuangan.

(2) Ganti kerugian sebagaimana dimaksud ayat (1) huruf b angka 2 hanya digunakan untuk pembayaran ganti kerugian kepada pihak yang dirugikan.

Selain di Undang Undang Nomor 21 tahun 2011 tetntang Otoritas Jasa Keuangan, para pelaku tindak kejahatan skimming juga bisa di tindak berdasarkan Pasal 32 ayat (1) Undang-undang No. 19 Tahun 2016 tentang Perubahan atas Undang-Undang No. 11 Tahun 2008 tentang Informasi dan Transaksi Elektronik (UU ITE) dalam kejahatan pembobolan ATM dengan metode skimming terdapat delik yang dilakukan oleh pelaku, yaitu melakukan tranmisi, merusak, menghilangkan, dan memindahkan suatu informasi elektronik atau dokumen elektronik milik orang lain atau publik karena dalam penggunaan skimmer pelaku melakukan tranmisi dengan cara melakukan pengiriman informasi elektronik dari ATM korban pada ATM yang dibuat oleh pelaku untuk diakses dan digunakan untuk mengambil uang korba melalui mesin ATM, sehingga dengan adanya Undang Undang ITE aparat kepolisian telah mempunyai landasan hukum untuk mengambil tindakan penyelidikan dan penyidikan kejahatan kartu ATM dan transaksi elektronik lainnya.

Undang - Undang No. 11 Tahun 2008 telah diubah oleh Undang - Undang No 19 Tahun 2016 informasi dan transaksi elektronik Pasal 46 yang berbunyi :

1) Setiap Orang yang memenuhi unsur sebagaimana dimaksud dalam Pasal 30 ayat (1) dipidana dengan pidana penjara paling lama 6 (enam) tahun dan/atau denda paling banyak

Rp600.000.000,00 (enam ratus juta rupiah).

2) Setiap Orang yang memenuhi unsur sebagaimana dimaksud dalam Pasal 30 ayat (2) dipidana dengan pidana penjara paling lama 7 (tujuh) tahun dan/atau denda paling banyak

Rp700.000.000,00 (tujuh ratus juta rupiah)

3) Setiap Orang yang memenuhi unsur sebagaimana dimaksud dalam Pasal 30 ayat

(3) dipidana dengan pidana penjara paling lama 8 (delapan) tahun dan/atau denda paling banyak Rp800.000.000,00 (delapan ratus juta rupiah)

Pada Pasal 30 berbunyi :

1) Setiap Orang dengan sengaja dan tanpa hak atau melawan hukum mengakses Komputer dan/atau Sistem Elektronik milik Orang lain dengan cara apa pun.

2) Setiap Orang dengan sengaja dan tanpa hak atau melawan hukum mengakses Komputer dan/atau Sistem Elektronik dengan cara apa pun dengan tujuan untuk memperoleh Informasi Elektronik dan/atau Dokumen Elektronik.

3) Setiap Orang dengan sengaja dan tanpa hak atau melawan hukum mengakses Komputer dan/atau Sistem Elektronik dengan cara apa pun dengan melanggar, menerobos, melampaui, atau menjebol sistem pengamanan. 
Adapun ayat 32 Undang-Undang Republik Indonesia Nomor 19 Tahun 2016 Tentang Perubahan Atas Undang-Undang Nomor 11 Tahun 2008 Tentang Informasi Dan Transaksi Elektronik, berbunyi

(1) Setiap Orang dengan sengaja dan tanpa hak atau melawan hukum dengan cara apa pun mengubah, menambah, mengurangi, melakukan transmisi, merusakk, menghilangkan, memindahkan, menyembunyikan suatu Informasi Elektronik dan/atau Dokumen Elektronik milik Orang lain atau milik publik.

(2) Setiap Orang dengan sengaja dan tanpa hak atau melawan hukum dengan cara apa pun memindahkan atau mentransfer Informasi Elektronik dan/atau Dokumen Elektronik kepada Sistem Elektronik Orang lain yang tidak berhak.

(3) Terhadap perbuatan sebagaimana dimaksud pada ayat (1) yang mengakibatkan terbukanya suatu Informasi Elektronik dan/atau Dokumen Elektronik yang bersifat rahasia menjadi dapat diakses oleh publik dengan keutuhan data yang tidak sebagaimana mestinya.

Jakarta, Kompas, Com ( 28 Maret 2018 ) Selain itu terhadap dana nasabah yang hilang karena kejahatan skimming, Otoritas Jasa Keuangan ( OJK) meminta bank-bank yang terdampak tindak kejahatan skimming untuk mengecek seluruh mesin ATM yang dimilikinya. Ini dilakukan guna memastikan mesin ATM tidak dipasangi perangkat skimmer atau kamera tersembunyi. OJK pun menyatakan bakal selalu mengevaluasi manajemen risiko sistem keamanan perbankan. Selain itu, bank-bank juga harus mengganti dana nasabah yang hilang karena menjadi korban kejahatan skimming. "Bagi nasabah yang dirugikan karena skimming, bank akan menggantinya. Kartu ATM disarankan diganti yang pakai cip," ujar Deputi Komisioner Pengawas Perbankan III OJK Slamet Edy Purnomo di Jakarta, Rabu (21/3/2018). Baca juga : Antisipasi Skimming, Bank Mandiri Perketat Patroli ke Mesin ATM Dia mengatakan, kejahatan skimming yang telah diungkap merupakan nasabah dari BRI dan Bank Mandiri. Meski demikian, Slamet tidak menyebutkan bank lain yang terkena kejahatan skimming selain kedua bank tersebut. "Sudah ada datanya. BRI dan Bank Mandiri, tapi semua (dana) diganti bank," jelas Slamet. Adapun Pengamat Ekonomi dan Perbankan dari Institute for Development of Economics and Finance (INDEF) Bhima Yudhistira Adhinegara menuturkan, kejahatan skimming telah terjadi di Indonesia sejak tahun 2014. Kejahatan skimming juga pernah terjadi di negara maju macam Inggris dan Jerman. Untuk itu, agar terhindar dari kasus skimming, perbankan harus secara teratur mengecek mesin ATM dan mengingatkan kembali nasabah untuk lakukan penggantian PIN secara rutin

\section{Upaya yang di lakukan Bank untuk mencegah Tindakan kejahatan Skimming.} Upaya-upaya/mitigasi yang dilakukan Bank dalam hal ini penulis melakukan wawancara dengan Bapak Wawan Suprianto, Branch Operation dan Service Manager , Bank Syariah Mandiri Cabang Pangkalan Bun , Kalimantan Tengah, adalah

a. Menginfokan kepada nasabah agar segera mengganti kartu magnetic strip menjadi kartu ATM GPN (Gerbang Pembayaran Nasional) yang berstandar Bank Indonesia. Sehingga upaya yang paling efektif untuk mencegah terjadinya skimming adalah mengganti kartu debit dari teknologi pita magnetik ke kartu yang dilengkapi cip. Sebab, data nasabah yang bisa diambil oleh pelaku kejahatan adalah yang tersimpan di kartu yang dilengkapi pita magnetik. Kini Indonesia telah memiliki sistem pembayaran domestik bernama Gerbang Pembayaran Nasional (GPN) dimana sistem ini mengintegrasikan berbagai instrumen kanal pembayaran secara nasional. Dilengkapi dengan teknologi chip untuk memberikan keamanan transaksi finansial. Nasabah bisa 
menggunakan Kartu Debit/ATM Domestik berlogo Nasional (GPN) tidak hanya pada mesin EDC atau terminal ATM Bank tertentu saja melainkan di mesin EDC atau terminal ATM Bank apapun yang memiliki logo GPN di seluruh Indonesia.

b. Mengedukasi Nasabah agar hati hati dalam melakukan transaksi di mesin ATM, perhatikan keadaan mesin ATM, apakah ada yang mencurigakan. Pilih lokasi ATM yang aman, jangan memilih transaksi di mesin ATM yang lokasinya sepi, selain itu pihak perbankan harus secara rutin memberikan informasi dan sosialisasi kepada nasabahnya untuk selalu berhati-hati menggunakan kartu ATM, bagaimana mengenali ruang ATM standar, cara menggunakan ATM yang aman, serta call center yang benar untuk layanan informasi pengaduan terhadap pemilik kartu ATM, karena banyak di temukan stiker yang di tempel pada mesin ATM yang menginfokan nomor Call Center yang salah yang di tempel oleh orang yang tidak bertanggung jawab.

c. Mensosialisasikan kepada nasabah untuk sering sering mengganti PIN, karena ketika kartu ATM di Skimming ketika nasabah melakukan penggantian PIN ATM, maka perekaman data nasabah pada kartu tersebut akan teracak dan tidak berfungsi lagi.

d. Pihak perbankan juga sudah memasang Pin Pad dan CCTV , di mana Pin Pad yang di letakan di atas tombol mesin ATM berfungsi untuk mencegah dan meminimalkan resiko perekaman PIN nasabah oleh kamera pengintan, sedangkan CCTV berfungsi untuk merekam kegiatan nasabah di mesin ATM sehingga bila terjadi hal hal yang tidak di inginkan bank dapat menelusuri kejadian tersebut dari rekaman CCTV yang ada

\section{Kendala yang di hadapi Bank dalam pencegahan tindakan kejahatan Skimming.}

a. Seperti yang penulis kutip dari economi.okezone.com PT Bank Rakyat Indonesia memaparkan kendalanya dalam migrasin kartu debit dari pita magnetic (magnetic strip) ke teknologi chip. Sebagaimana di ketahui Bank Indonesia agar perbankan menggunakan tecnologi chip pada kartu debit sebagai antisipasi adanya kejahatan cyber ( cyber crime) yang salah satunya adalah skimming. Menurut Direktur Utama BRI Suprajarto, memaparkan kendala yang di alami perseroan adalah dalam proses pembuatan chip iti sendiri. Sebab fihak yang memiliki kewenangan untuk mencetak chip yang memiliki kode keamanan sangat terbatas yaitu Percetakan Negara Republik Indonesia (PNRI) dan Percetakan Uang Republik Indonesia (Peruri). Di mana saat ini kedua perusahaan tersebut kebanjiran order pembuatan teknologi cip dalam kartu debit.

Hal ini setelah BI meminta bank besar mempercepat implementasi cip dalam kartu debit. BI ingin agar sampai akhir tahun ini sudah lebih dari 30\% kartu debit bank menggunakan teknologi cip. Suprajarto, Direktur Utama BRI bilang perusahaan yang bisa mencetak teknologi cip dalam kartu debit terbatas. "Kalau kita memproses pembuatan cip ini, perusahaan yang bisa melayani terbatas," kata Suprajarto dalam paparan kinerja, ( Kontan.co.id,) Kamis ,3 Mei 2018.

Apalagi saat ini hampir semua bank besar ingin mempercepat proses pencetakan kartu cip. Perusahaan seperti PNRI dan Peruri juga tidak bisa menaikkan kapasitas secara drastis. Hampir semua perbankan minta itu (kartu chip), oleh karena itu mereka kapasitasnya enggak bisa dinaikkan jadi puluhan juta ini perlu ada tahapan," ujarnya di Kantor BRI Pusat, Jakarta, Kamis (3/5/2018). Dengan jumlah nasabah sekitar 70 juta orang, Suprajarto mengatakan bahwa BRI membutuhkan proses yang tentunya lebih memakan waktu ketimbang bank dengan nasabah lebih sedikit. 
b. Ketua Komite VII ASPI Santoso Liem mengungkapkan, saat ini industri perbankan telah memulai transisi penggunaan chip dari pita magnetik pada kartu ATM dan/atau kartu debit. Kendati demikian, Santoso memperkirakan jumlah kartu ATM dan/atau debit yang disertai chip masih kurang dari 10 persen dari total kartu yang beredar. Menurut Santoso, dari segi keamanan, kartu yang disertai chip memang lebih aman. Pasalnya, kartu chip lebih sulit digandakan dibandingkan kartu yang memiliki pita magnetik. Dengan demikian, risiko mengalami kejahatan dengan modus skimming bisa lebih kecil bagi nasabah. Namun, menurut dia, biaya pencetakan kartu chip lebih mahal dibandingkan kartu pita magnetik. Sebagai pembanding, Santoso menyebutkan biaya produksi satu keping kartu pita magnetik hanya sekitar 20 hingga 25 sen dolar AS. Sementara itu, biaya produksi satu keping kartu chip mencapai US\$1.( CNN Indonesia | Rabu, 21/06/2017)

\section{PENUTUP}

\section{Kesimpulan}

1. Untuk Perlindungan hukum terhadap nasabah Bank sudah terlindungi dengan Undang Undang Nomor 21 tahun 2011 tetntang Otoritas Jasa Keuangan. Dan Undang-Undang Republik Indonesia Nomor 19 Tahun 2016 Tentang Perubahan Atas Undang-Undang Nomor 11 Tahun 2008 Tentang Informasi Dan Transaksi Elektronik.

2. Bank Juga harus melakukan pencegahan terhadap tinadakan Skimming dngan cara,

- Menginfokan kepada nasabah agar segera mengganti kartu magnetic strip menjadi kartu ATM GPN (Gerbang Pembayaran Nasional) yang berstandar Bank Indonesia yang sudah di lengkapi Chip.

- Mengedukasi Nasabah agar hati hati dalam melakukan transaksi di mesin ATM.

- Mensosialisasikan kepada nasabah untuk sering sering mengganti PIN,

- Pihak perbankan agar memasang Pin Pad dan CCTV.

3. Kendala yang dihadapi Bank dalam dalam pencegahan tindakan kejahatan Skimming adalah :

- Pada proses pembuatan chip iti sendiri. Sebab fihak yang memiliki kewenangan untuk mencetak chip yang memiliki kode keamanan sangat terbatas yaitu Percetakan Negara Republik Indonesia (PNRI) dan Percetakan Uang Republik Indonesia (Peruri). Di mana saat ini kedua perusahaan tersebut kebanjiran order pembuatan teknologi cip dalam kartu debit.

\section{Saran}

- Mahalnya biaya pembuatan kartu ATM bertekhnologio Chip

Bank selain menggganti uang nasabah juga agar selalu melaporkan setiap kejahatan skimming ke pihak yang berwajib untuk di proses secara hukum dan dihukum dengan hukuman maksimal untuk memberi efek jera pada para pelaku ataupun yang berniat untuk melakukan kejahatan skimming.

\section{DAFTAR PUSTAKA}

\section{Buku}

Budi Suhariyanto, 2013. Tindak Pidana Teknologi Informasi (Cybercrime): Urgensi Pengaturan dan Celah Hukumnya, Jakarta: Rajawali Press, 
Lukman Santoso, 2011. Hak dan Kewajiban Hukum Nasabah Bank, Pustaka Yustisia,.

Jurnal

Dian Ekawati Fakultas Ilmu Hukum, Universitas Pamulang Perlindungan hukum terhadap nasabah bank yang dirugikan akibat kejahatan skimming ditinjau dari perspekti teknologi informasi dan perbankan

\section{Undang Undang}

Undang Undang RI nomor 10 Tahun 1998 tanggal 10 November 1998 tentang Perbankan Undang Undang RI Nomor 21 tahun 2011 Tetnatng Otoritas Jasa keuangan.

Undang-Undang Republik Indonesia Nomor 19 Tahun 2016 Tentang Perubahan Atas Undang-Undang Nomor 11 Tahun 2008 Tentang Informasi Dan Transaksi Elektronik.

\section{Internet}

CNN Indonesia | Rabu, 21/06/2017 )

Detik News, 18 Maret 2018

Economi.okezone.com

Investor Daily.

Kontan.co.id,) Kamis ,3 Mei 2018.. 
